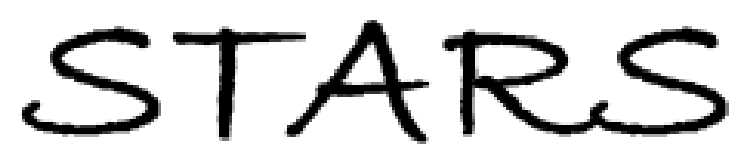

University of Central Florida

STARS

$1-1-2008$

\title{
Analysis of Japanese Hotel Employees' Job Satisfaction and Its Association with Annual Income and Other Socio-Economic Variables
}

Tadayuki Hara

University of Central Florida, tadayuki.hara@ucf.edu

Dana Tesone

University of Central Florida, dana.tesone@ucf.edu

Part of the Hospitality Administration and Management Commons, and the Tourism and Travel Commons

Find similar works at: https://stars.library.ucf.edu/rosenscholar University of Central Florida Libraries http://library.ucf.edu

This Paper is brought to you for free and open access by the Rosen College of Hospitality Management at STARS. It has been accepted for inclusion in Rosen Faculty Scholarship and Creative Works by an authorized administrator of STARS. For more information, please contact STARS@ucf.edu.

\section{Original Citation}

Hara, T. \& Tesone, D.V. (2009). Analysis of Japanese hotel employees' job satisfaction and its association with annual income and other socio-economic variables. International Journal of Tourism Science. 8(1), 71-88.

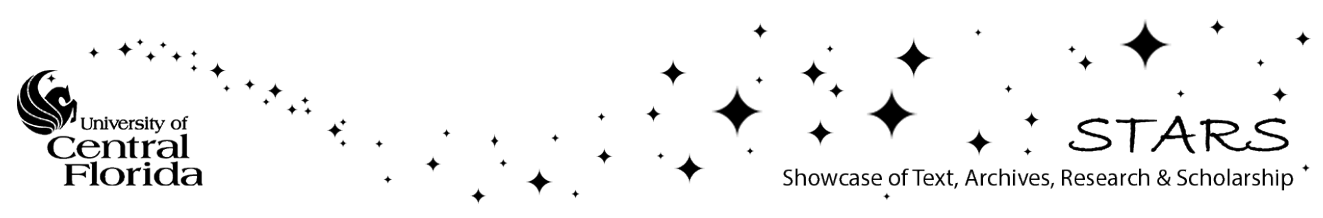




\section{Analysis of Japanese Hotel Employees' Job Satisfaction and Its Association with Annual Income and Other Socio-Economic Variables}

\section{Tadayuki(Tad) Hara \& Dana Tesone}

To cite this article: Tadayuki(Tad) Hara \& Dana Tesone (2008) Analysis of Japanese Hotel Employees' Job Satisfaction and Its Association with Annual Income and Other Socio-Economic Variables, International Journal of Tourism Sciences, 8:1, 71-88, DOI: 10.1080/15980634.2008.11434605

To link to this article: http://dx.doi.org/10.1080/15980634.2008.11434605

\section{曲 Published online: 03 Jun 2015.}

Submit your article to this journal $\llbracket$

Џلl Article views: 7

Q View related articles $\longleftarrow$ 


\title{
ANALYSIS OF JAPANESE HOTEL EMPLOYEES' JOB SATISFACTION AND ITS ASSOCIATION WITH ANNUAL INCOME AND OTHER SOCIO-ECONOMIC VARIABLES*
}

\author{
Tadayuki(Tad) Hara** \\ University of Central Florida \\ Dana Tesone*** \\ University of Central Florida
}

\begin{abstract}
Researcher conducted quantitative analyses of Japanese hotel employees' job satisfaction and its association with the other variables such as actual annual salary, desired annual salary, age, gender, highest education, years in the industry, number of jobs switched, size of the hotel etc. While some of the descriptive statistics might indicate that overall mean score of the job satisfaction appears to be improving, the research revealed where the increased variances of satisfaction might have come from. Series of hypotheses testing based on the industry-generated questions were conducted. While there were
\end{abstract}

* The author is indebted to several individuals to generate this preliminary research paper. Dr. Dana Tesone, Associate Professor, Rosen College of Hospitality Management, University of Central Florida rendered enormous help indirecting the author towards appropriate direction for the research. Mr. Masahiro Ishiwata, Associate Editor, Shukan Hotel Restaurant at Ohta Publications, Tokyo, Japan allowed the author to have access to their proprietary data and granted permission to generate academic research for the sake of advances of Japanese Hotel industry. Preliminary summary of analyses were disseminated in their journal "Shukan Hotel Restaurant" May 9, 2008 issue in Japanese. The author expresses appreciation for the aspirations generated through exchanges of opinions and constructive dialogues with faculty members at Economics Department of Yamaguchi University under the auspices of "academic research promotion funding of the Economics Department of Yamaguchi University, Japan (Heisei 18 nendo Gakujyutu Shinko Kikin Josei)".

** Associate Professor, Rosen College of Hospitality Management, University of Central Florida, USA, E-mail: thara@mail.ucf.edu

*** Associate Professor, Rosen College of Hospitality Management, University of Central Florida, USA. 
substantial evidences to support some allegations, relatively huge variances often indicated that the reality around the job satisfaction would be more complicated than simple linear modeling can explain its variances.

Keywords: hotel, job satisfaction, annual income 


\section{INTRODUCTION}

While it is the second largest economy of the world in terms of GDP, research on the hotel industry in Japan has been rarely disseminated in English. With increasing supply of new hotels in metropolitan cities to catch up with high demand for hotel rooms (nationwide occupancy rates for 2005, 2006 and 2007 were 68.1\%, 70.1\%, 69.9\% respectively: Shukan Hotel Restaurant 2008), combined with dwindling numbers of younger workforce in Japan, Japanese hotel labor market is experiencing shortage of labor. Having been known for its life-time employment system in the last few decades, however, Japanese labor market started to show more liquidity, in a sense that head-hunting and voluntary changes of employers in search for better careers became more of a norm than an exception.

Stakeholders in the Japanese hotel industry, including owners, investors and managers started to express their specific needs to identify some directions about better management and retention of the existing labor forces, while hotel employees became more eager to know their relative positioning in a broader hotel labor market in Japan.

The main purpose of this study is to extract useful managerial information for Japanese hotel management and owners regarding their employees' perceptions to be measured by multiples of variables. Those variables include current job satisfaction level, gender, age, years in the jobs, numbers of previous job changes, highest educational level, type of employment contract, title, actual annual income, desired annual income, geographical region etc. The goal of the study is to present suggested actions or inactions to the management of the Japanese hotel businesses so that they can increase the likelihood of retaining current labor forces. Related benefits may be found by employees of the hotel industry as to put themselves in relative terms with the nationwide data of the larger samples.

The author acknowledges generous permission by one of the two leading hotel-restaurant management journals in Japan, Shukan Hotel Restaurant by Ohta 
Publications, enabling the author to analyze sets of quantitative data to draw some managerial implications. Preliminary results were

\section{LITERATURE REVIEW}

There are series of studies on job satisfaction of hotel employees. In one study, respondents reported the most satisfaction with the job introduction factor and the least satisfaction with the compensation factor. The department/work team climate factor had the greatest correlation with overall job satisfaction (Mount \& Bartlett 2002). In the case of hotel workers in Northern Cyprus, researchers found that job satisfaction exerts a significant positive influence on affective organizational commitment. The model test results also demonstrated that job satisfaction and affective organizational commitment are negatively associated with intention to leave. (Karatepe, Arasli \& Khan 2007)

There is one study where researchers found that differences are evident in certain aspects of employee satisfaction based on size and service type. (Mount \& Frye 2006) When the same researchers came back to study about the effect of hotel size and service type over job satisfaction, they did not find what they had previously Researchers concluded that neither hotel size nor service type significantly impacted general manager job satisfaction and gender, age, educational level, and longevity in the hospitality industry or as a hotel manager all had minimal impact on job satisfaction (Frye \& Mount 2007). One research was made with the data colleted from hotels in San Diego, CA, USA, regarding usage of human resources management types and affect over job satisfactions and other variables. The study concluded that varieties of human resource management style had a statistically significant relationship with job satisfaction, morale, and optimism about the future of the hotel. These attitudes, in turn, were significantly related to turnover intentions. (Chow, Haddad \& Singh 2007) One study with Turkish hotel employees concluded that such attributes as the work itself, supervision, and promotion are the determinants of the level of overall job satisfaction. The level of overall job satisfaction in turn leads to changes in the employees' intention to continue working in the hotel business (Tutuncu \& Kozak 2007). 


\section{DATA}

The prime data were collected by online questionnaire HTML format from the readers of "Weekly Hotel Restaurant" Journal, Ohta Publication, Tokyo Japan in early 2008. Original questionnaires and results were all in Japanese language, which are translated into English for the purpose of this study. Valid answers account for 300 samples. Summary of translated questionnaires were attached as an Appendix 1.

\section{METHODOLOGY}

Collected data were analyzed first by descriptive statistics, followed by several hypotheses testing of the inferential statistics. Non-linear logistic regression was used for the binary dependent variable of gender. As for the estimation of annual salary as dependent variable, multivariate linear regression model was used. Finally non-parametric, data-plotting were utilized to find some patterns of the plotted variables.

\section{FINDINGS}

\section{Descriptive Statistics}

Overview of the data reveals an interesting trend with the job satisfaction data. Compared with the previous year's descriptive data, overall mean for job satisfaction improved for both male and female workers. Male workers show their satisfaction rating ( 1 = very dissatisfied, $5=$ very satisfied) improved from 2.095 to 2.137 and female workers' mean moved from 1.919 to 1.955 . The improvement with the mean data may hide problems hidden behind the basic descriptive statistics, unless we look at standard deviations of those data. Standard deviation for the male workers increased from 0.9369 to 1.136 , and one for female workers also increased from 0.9231 to 1.224. 


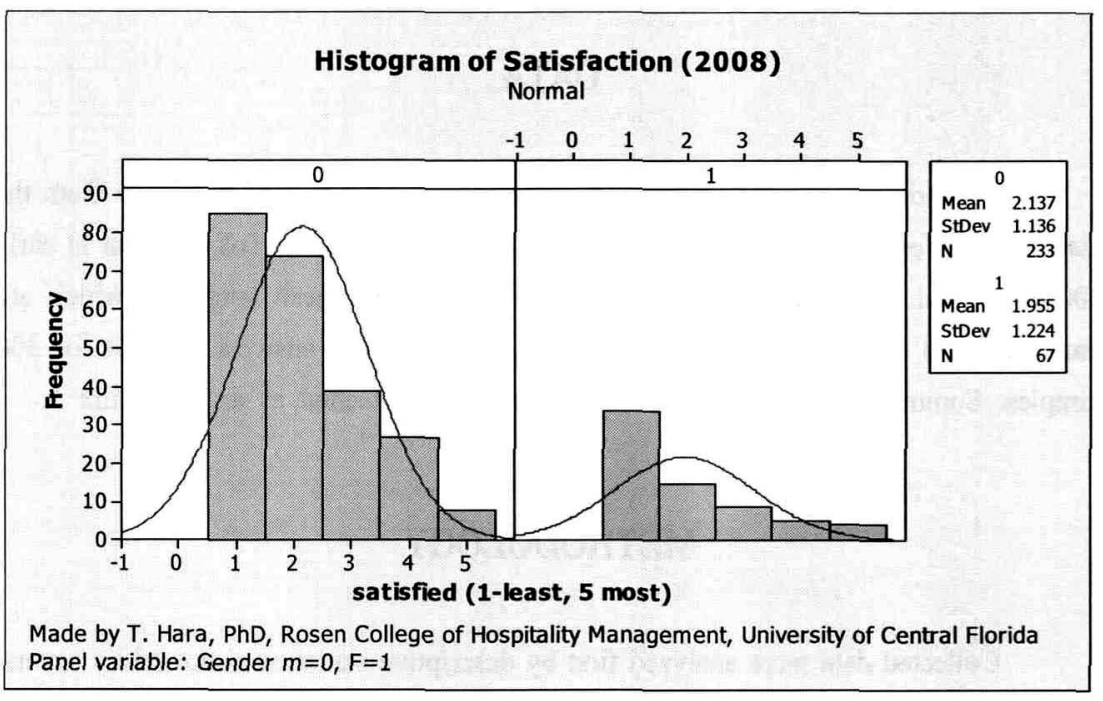

Figure 1. Japanese Hotel Employees' Satisfaction in 2008 (Left: $0=$ male, Right: $1=$ female)

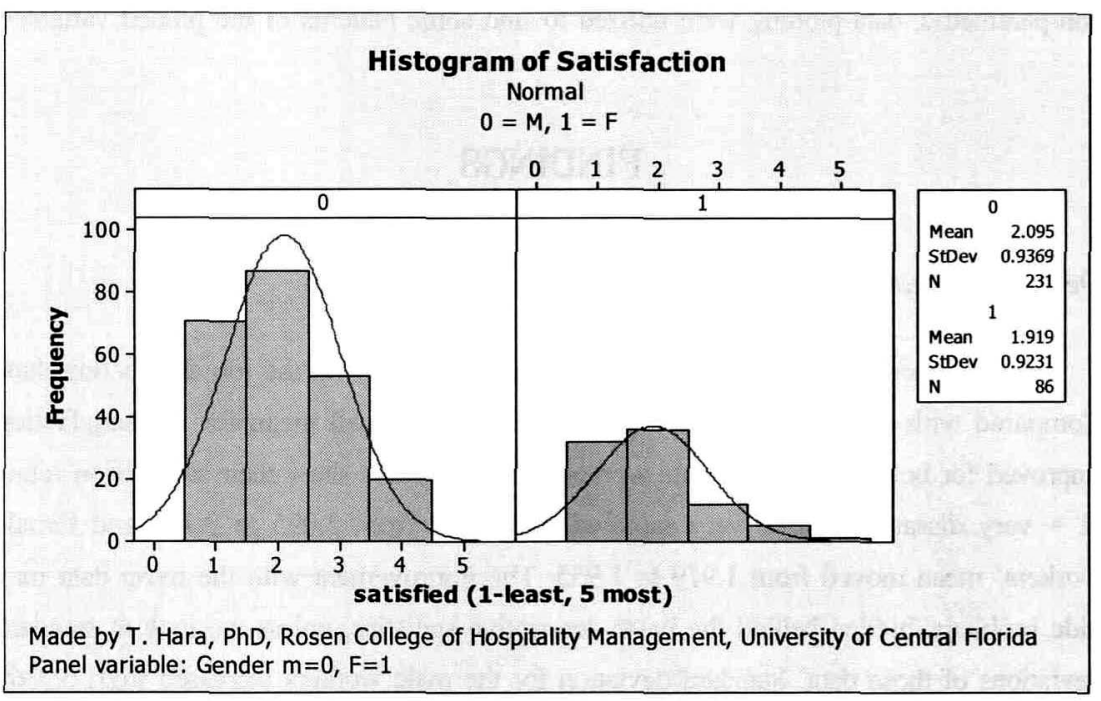

Figure 2. Japanese Hotel Employees' Satisfaction in 2007 (Left: $0=$ male, Right: $1=$ female) 
Even though the comparative analysis of two year data on Japanese hotel employees' satisfaction appear to be improving on the surface, there appears to be disturbing increase of variances both male and female workers. This may be a troubling issue, as it is believed that happy employees are critical parts of hotel operation to create happy customers. Without satisfied employees, Japanese hotel industry may face difficulty in delivering desired service levels to satisfy customers. Now we will investigate the data further by using inferential statistical analyses on various issues.

\section{INFERENTIAL STATISTICS}

Based on series of assumptions expressed by industry practitioners, we will conduct a set of hypothesis testing whether there would be any association between job satisfaction level of Japanese hotel workers and other socio-economic variables.

(1) Current Annual Income Level and Job Satisfaction

"Can money buy satisfaction of Japanese Hotel workers?"

Technically, we create a pair of hypotheses, one called the null hypothesis asserting that there is no association between their job satisfaction and current annual income, and the other called alternative hypothesis saying that we have enough statistical evidence(s) to refute the null hypothesis. It implies that we have enough statistical evidence(s) to indicate existence(s) of association between those variables in question.

We conducted a simple linear regression with one independent variable (current annual income) and a dependent variable of job satisfaction. The result is shown in Table 1. 
Table 1. Results of Analysis: Job Satisfaction and Annual Income Level

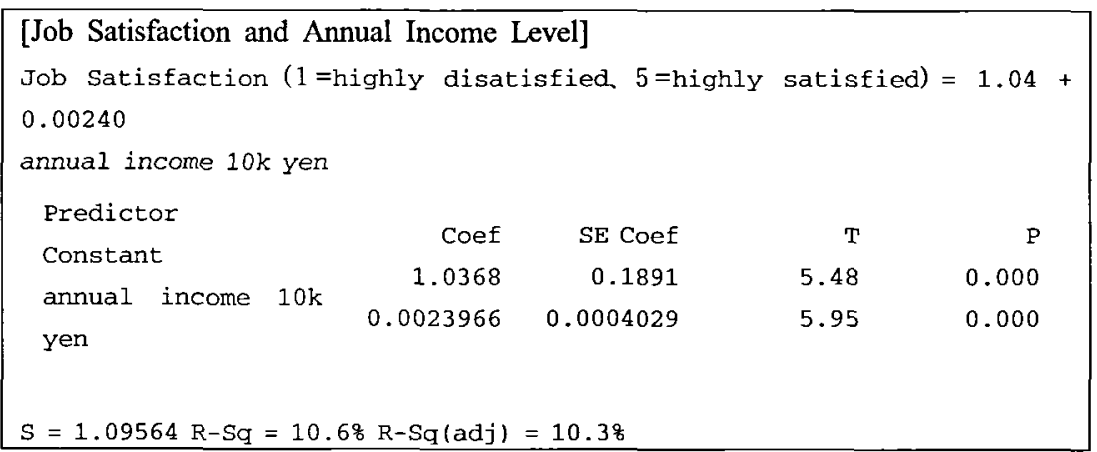

Source: made by the author

This result surely indicated that management/owners can surely buy job satisfaction as shown by high $\mathrm{T}$-ratio of 5.95 , which indicated a very convincing existence of positive association between the job satisfaction level and their annual income. In technical terms, we have enough statistical evidences to refute the null hypothesis which asserted no association between those two variables, and thus we have enough evidences to support the alternative hypothesis At the same time, the R-square is shown as $10 \%$ only, which told us that only $10 \%$ of variances of job satisfactions are explained by this simple linear regression model. This indicated that life was not as simple as some wished where you can buy higher employee satisfaction by higher offer of salary.

(2) Relative Difference between Desired and Actual Annual Income and Job Satisfaction "Is job satisfaction related to your perceptional gap between the desired and actual annual income?"

Some argues that Japanese hotel employees' job satisfaction can be measured by the gap between the annual income they wish to receive and what they actually receive. What are assumed would be an existence of inverse association between the relative size of gap (between desired and actual income) and the level of job satisfaction. In order to standardize the difference between each respondent's responses, the absolute 
difference between desired and actual income was divided by the respondent's actual annual salary. The result is shown in Table 2.

Table 2. Result of Analysis: Relative Difference between Desired and Actual Annual Income and Job Satisfaction

[Relative difference between Desired and Actual Annual Income and Job Satisfaction]

Job Satisfaction ( 1 =highly disatisfied, $5=$ highly satisfied) $=$

2.85 - 3.19 Relative Difference between Desired and Actual Income

$\begin{array}{rrrrr}\text { Predictor } & \text { Coef } & \text { SE Coef } & T & P \\ \text { Constant } & 2.8546 & 0.1144 & 24.95 & 0.000 \\ \text { Dif/base } & -3.1934 & 0.4081 & -7.83 & 0.000\end{array}$

$S=1.05547 \mathrm{R}-\mathrm{Sq}=17.08 \mathrm{R}-\mathrm{Sq}(\operatorname{adj})=16.8 \%$

Source: made by the author

This simple linear regression revealed a significant existence of inverse association between the relative gap and the job satisfaction level as shown with $\mathrm{T}$ ratio of -7.83 . The larger the relative gap, the less the job satisfaction of a worker would be. This model, however explains only $17 \%$ of the variances of the job satisfaction levels, which means there would be some other issues responsible for the other $83 \%$ of the variances of job satisfaction level. Before we proceed further, this model can answer one important question by the hotel management/owners about the employee satisfaction whether employees would be completely satisfied to be paid exactly the annual income they desired. Putting zero in the equation for the relative gap, the job satisfaction level $=2.85-3.19 \times 0=2.85$. Even if the management/owners provide completely what employees wanted, job satisfaction level does not even reach the median default score of 3.00 . This would be considered as a reminder for the management/owners of Japanese hotels of the complexity of job satisfaction issues.

(3) Multivariate Linear Regression Modeling: Job satisfaction and other variables [age, current annual income, relative differences between desired and actual income] 
With a hope to improve the explanatory power for the variances, we utilized the multivariate linear regression model in which there are more than two independent variables in pursuit for better explanations for the same dependent variable - job satisfaction. We used the age (continuous variable as we obtained actual ages of respondents), actual annual income and the gap between desired and actual income. The results are shown in Table 3 .

Table 3. Result of Analysis: Age, Annual Income, Relative Difference between Desired and Actual Annual Income and Job Satisfaction

\begin{tabular}{|c|c|c|c|c|}
\hline \multicolumn{5}{|c|}{$\begin{array}{l}\text { Multivariate Linear Regression Model: Age, Annual Income and the Gap between } \\
\text { Desired and Actual Income } \\
\text { Job Satisfaction }(1=\text { highly disatisfied, } 5=\text { highly satisfied) }= \\
2.77-0.0349 \text { Age }+0.00284 \text { Annual Income }-2.95 \text { Relative Gap between Desired } \\
\text { and Actual Income }\end{array}$} \\
\hline \\
\hline \multicolumn{5}{|c|}{$\begin{array}{lrr}\text { Predictor } & \text { Coef } & \text { SE Coef } \\
\text { Constant } & 2.7731 & 0.3603\end{array}$} \\
\hline \multirow{2}{*}{$\begin{array}{l}\text { Age } \\
\text { Actual Annual } \\
\text { Income }\end{array}$} & -0.03488 & 0.01184 & -2.94 & 0.003 \\
\hline & 0.0028382 & 0.0004786 & 5.93 & 0.000 \\
\hline \multicolumn{2}{|l|}{ (desired \& actual) } & 0.3929 & & 0.000 \\
\hline
\end{tabular}

Source: made by the author

There appeared to be significant inverse relationship between age and job satisfaction, indicating that as employees ages, their job satisfaction level tend to go down, but as their actual annual income increase, such negative pressure over the job satisfaction level is mitigated with positive association between annual income and job satisfaction. The relative gap between desired and actual income would spoil this relationship even though this would not be able to lift up the job satisfaction effectively as we leamed in the previous model. We saw a better R-square of $25.3 \%$ indicating that this multivariate linear regression model can explain $25 \%$ of the variances of the job satisfaction level of Japanese hotel workers.

(4) Multivariate Linear Regression Model: Estimating an Appropriate Salary 


\section{Level given Various Socio-Economic Variables}

It is a daunting task for hotel managers/owners to figure out the appropriate annual income level for a employee, due to many confounding factors such as personalized situations, skill sets, previous job experiences, etc. We made an attempt to create a highly standardized model to predict an appropriate salary levels given various data of the respondents.

Table 4. Results of Japanese Hotel Employees Annual Salary Prediction Model

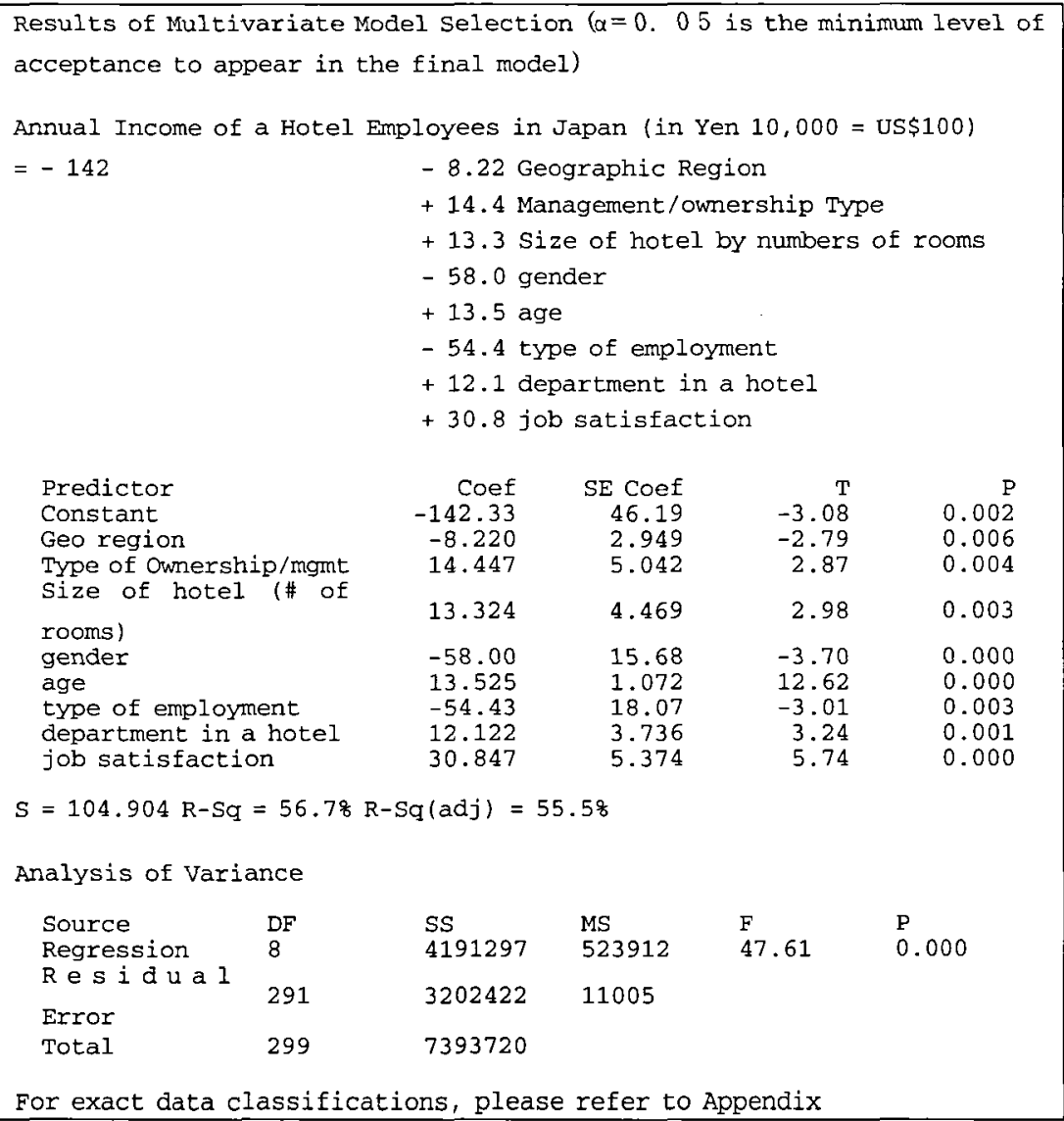

Source: made by the author 
This model turned out to be able to explain more than half of the variances of the annual income of hotel employees. As noted, all the independent variables in this model are significant at $95 \%$ of the occurrences of the salary prediction. Age appears to be a very significant variable to explain the annual salary level of a hotel employee, indicating that existing of seniority-based employment practices are still traceable in the dataset.

\section{(5) Non-Linear Modeling: Logistic Regression}

We responded to a plea from the industry to verify whether there are any evidences of gender-based differences, or any sign of gender being a significant factor to explain other variables. What we did was to create a model in which gender would be treated as a binomial variable (with two outcomes only $=0$ or 1) and all other available variables are put as independent variable. It is a multivariate logistics regression model, which is not a linear modeling per se anymore. What we tried to accomplish was to identify where any variables turned out to be significant to identify the gender of the respondents. The results are shown in Table 5.

Table 5. Results of Non-Linear Logistics Regression

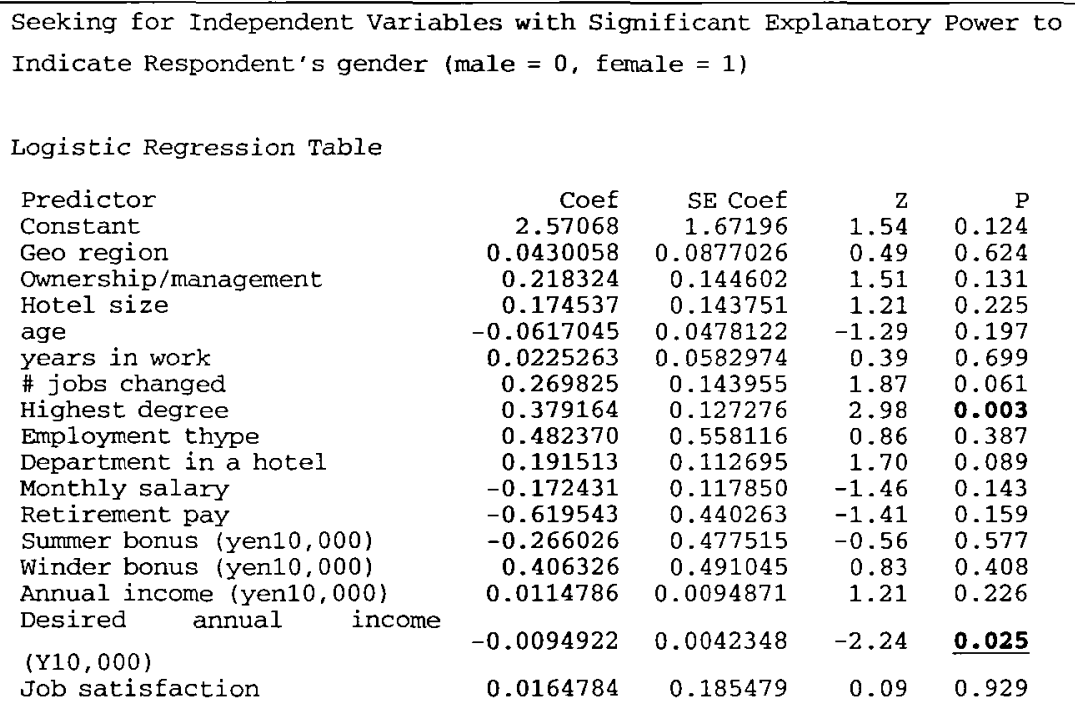


The interpretation of the model would be to check whether any independent variables had P-value smaller than 0.05 . We only identified two of such variables, the highest educational degree $(Z=2.98)$ and the desired annual income $(Z=-2.24)$. This implied that if a respondent had university degree or even a graduate degree, we could have identified that the person was female. And if the respondent had lower desired income, we could have predicted that the person was female. It is important to note that critical variables such as annual income did not come out as significant, indicating that we did not identify a significant trace of gender discrimination from the dataset.

(6) Non-Parametric Analysis: 3-D Data Plotting

Finally, we simply plotted the three important variables in the three-dimensional setting to check whether any interesting observation might be derived from the visual plotting. We picked up job satisfaction, highest educational degree, and the gender to see whether there were any interesting patterns of interactions among those three variables. We put satisfaction along the $\mathrm{Y}$-axis, gender along the $\mathrm{X}$-axis and the highest educational degree along the $\mathrm{Z}$-axis. The result is shown in Figure-3.

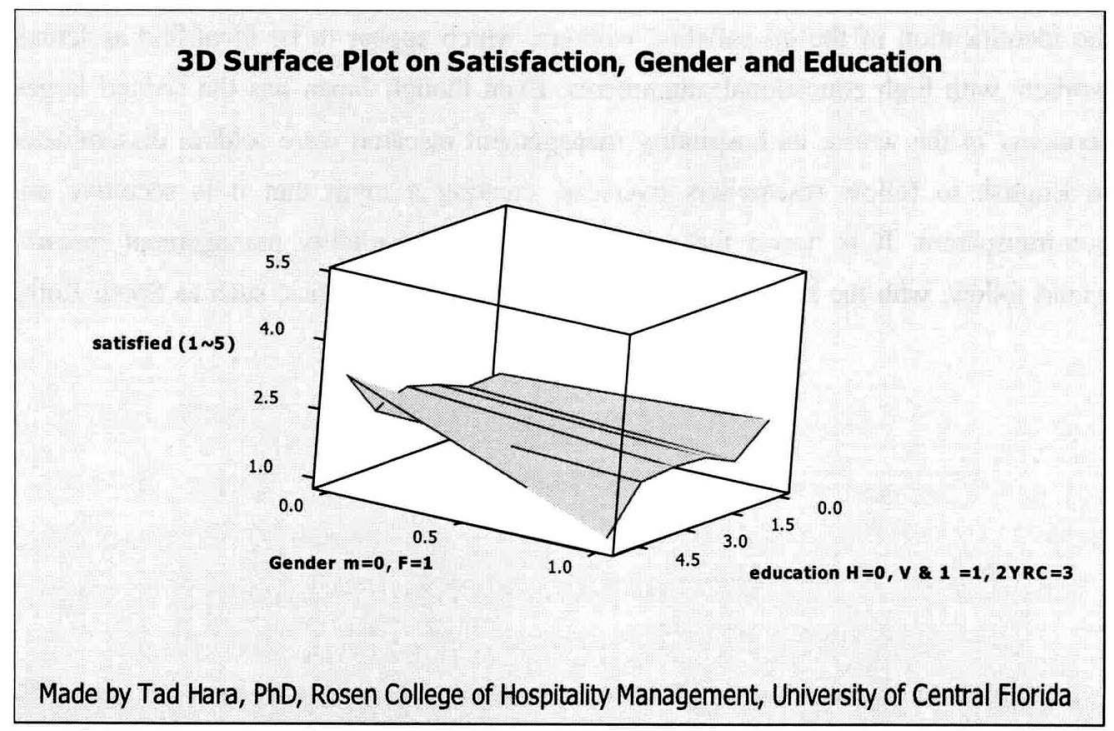

Figure 3. 3-D Surface Plot on Satisfaction, Gender and Education 
As we put the satisfaction along the height, we can conveniently see the object inside the cube as a flying carpet, so that we can see which point is higher (= more satisfied) and lower (=less satisfied) than the others. We can clearly see that decomposing the female into high-school graduate and university-degree reveals staggering difference of satisfaction levels within the female group. Also by looking at the university degree groups decomposed into the male and female group, we clearly see the very dissatisfied workforce exists with female workers within the university-degree holders. There appears to be a urgent need for Japanese hotel management/owners to reevaluate the utilization of female workforce with university degrees or higher.

\section{CONCLUSION}

Quantitative data analysis could reveal more managerial information that simple descriptive statistics can show. Given the wide-spread allegation that happy customers are created by happy employees, there appears to be several urgent tasks for Japanese hotel management and owners to deal with their employees. One of them would be the identification of the dis-satisfied workers, which appear to be identified as female workers with high educational attainments. Even though Japan has the second largest economy in the world, its hospitality management research were seldom disseminated in English to fellow researchers overseas, creating a myth that it is secretive and non-transparent. It is hoped that more quantitative hospitality management research would follow, with the help of more advanced neighboring nations, such as South Korea. 


\section{REFERENCES}

Chow, C., Haddad, K., Singh, G., (2007). Human Resource Management, Job Satisfaction, Morale, Optimism, and Turnover. International Journal of Hospitality \& Tourism Administration, 8(2), 73-88.

Frye, W.,Mount, D., (2007). An Examination of Job Satisfaction of General Managers Based on Hotel Size and Service Type. Journal of Human Resources in Hospitality \& Tourism, 6(2), 109-134.

Karatepe, O, Arasli, H., Khan, A., (2007). The Impact of Self-Efficacy on Job Outcomes of Hotel Employees: Evidence from Northern Cyprus. International Journal of Hospitality \& Tourism Administration, 8(4), 23-46.

Mount, D., Bartlett, B.(2002). Development of a Job Satisfaction Factor Model for the Lodging Industry. Journal of Human Resources in Hospitality \& Tourism, 1(1), 17-24.

Mount, D., Frye, W., (2006). The Impact of Hotel Size and Service Type on Employee Job Satisfaction. FIU Hospitality Review, 24(1), 60-68.

Tutuncu, O., Kozak, M.,(2007.) An Investigation of Factors Affecting Job Satisfaction. International Journal of Hospitality \& Tourism Administration, 8(1), 1-19. 


\section{Appendix: Summary of Translated Questionnaires}

Questionnaires items are as follows;

1. Location by Prefecture (there are about 50 possible answers. Due to small samples in some prefectures, data were grouped into 7 different geographical regions)

2. Hotel Ownership and Management Entities

a. Japanese Owner \& Japanese Operation $=1$

b. Japanese Owner \& Foreign Operator $=2$

c. Foreign Owner \& Japanese Operator $=3$

d. Foreign Owner and Foreign Operator $=4$

3. Hotel Size (\# of rooms as a proxy for size)
a. Less than 50 rooms
$=1$
b. $50 \sim 100$
$=2$
c. $101 \sim 300$
$=3$
d. $301 \sim 500$
$=4$
e. $501 \sim 700$
$=5$
f. Over 701
$=6$

4. Gender $($ Male $=0$. Female $=1)$

5. Age (real number $=$ continuous variable with integer)

6. Numbers of years in the current job (real number: some responded with decimal number)

7. Numbers of times the respondent changed jobs before current job 
8. Highest Education (high school $=0$, vocational school $=1$, two year college $=2$, four year university $=3$, graduate school $=4$ )

9. Job contract status (regular full-time with tenure $=0$, annual contract $=1$, part-time contract, including advisory $=2$ )

10. Job Function (categorical variable)

a. Front Area (front, rooms) $=0$

b. FB

$=1$

c. Banquet (big in Japan) $=2$

d. Sales and marketing $=3$

e. Administration-management $=4$

11. Vertical job title

a. No title or Associate $=0$

b. Assistant manager $=1$

c. Manager $=2$

d. Associate Director or AGM $=3$

e. Director or General Manager $\quad=4$

f. Head Office Director and above $=5$

12. Monthly salary (in 10,000 yen $=$ US $\$ 100$ )

13. Retirement Bonus system (none $=0$, yes $=1$, prepaid $=2$ )

14. Summer bonus (in 10,000 yen $=$ US $\$ 100$ )

15. Winter bonus (in 10,000 yen $=$ US $\$ 100$ )

16. Actual Annual Gross Income in 10,000 yen $=$ US\$100)

17. Desired amount of Annual Gross Income in 10,000 yen $=$ US $\$ 100$ ) 
18. Satisfaction with the current Job $(1=$ least satisfied, $5=$ most satisfied $)$

19. Different between Desired and Actual annual income standardized (by taking the difference divided by the actual amount)

Submitted May $25^{\text {th }} 2008$

Accepted Jun $21^{\text {th }} 2008$

Refereed anonymously 